\title{
Effects of CPAP on nitrate and norepinephrine levels in severe and mild-moderate sleep apnea
}

\author{
Paula Pinto ${ }^{1,2,3^{*}}$, Cristina Bárbara ${ }^{1,2,3}$, Joseph M Montserrat ${ }^{4}$, Rita S Patarrão ${ }^{2}$, Maria P Guarino ${ }^{2}$, Miguel M Carmo ${ }^{2}$,
} Maria P Macedo ${ }^{2}$, Cristina Martinho ${ }^{1}$, Rita Dias ${ }^{1}$ and Maria JM Gomes ${ }^{2,3}$

\begin{abstract}
Background: Reduced plasma nitrate $\left(\mathrm{NO}_{x}\right)$ levels and increased urinary norepinephrine (U-NE) levels have been described in severe obstructive sleep apnea (OSA), and are reverted by continuous positive airway pressure (CPAP). The effect of CPAP on these biomarkers in mild-moderate OSA is not well understood.

The aim of this study was to compare $\mathrm{NO}_{x}$ and U-NE levels and blood pressure (BP) between male patients with mild-moderate and severe OSA and determine the impact of 1 month of CPAP therapy on these parameters.
\end{abstract}

Methods: We undertook a prospective study of 67 consecutive OSA patients (36 mild-moderate, 31 severe). Measurements of plasma $\mathrm{NO}_{x}$ at $11 \mathrm{pm}, 4$ am and $7 \mathrm{am}, 24-\mathrm{h} \mathrm{U}$-NE and ambulatory BP were obtained at baseline and after 1 month of CPAP.

Results: At baseline, $\mathrm{NO}_{x}$ levels showed a significant decrease during the night in both groups $(\mathrm{p}<0.001)$. U-NE level and BP were significantly higher in the severe OSA group. After 1 month of CPAP, there was a significant increase in $\mathrm{NO}_{x}$ levels and a reduction in U-NE level and BP only in patients with severe OSA.

Conclusions: One month of CPAP results in significant improvements in $\mathrm{NO}_{x}$ levels, 24-h U-NE level and BP in patients with severe OSA, but not in patients with mild-moderate OSA.

Trial registration: ClinicalTrials.gov: NCT01769807

\section{Background}

Obstructive sleep apnea (OSA) is an increasingly recognized health issue. Considerable evidence supports an independent association between OSA and cardiovascular disease, which is particularly strong for systemic arterial hypertension [1-3]. The pathogenesis of this association is likely to be multifactorial, involving a diverse range of mechanisms including increased sympathetic activity, systemic inflammation, endothelial dysfunction, oxidative stress and metabolic dysregulation $[4,5]$.

Continuous positive airway pressure (CPAP) decreases daytime somnolence and prevents cardiovascular complications in patients with severe OSA [6,7]. However, there is no consensus on the cardiovascular benefits of CPAP therapy in mild-moderate patients. The impact of mild

\footnotetext{
* Correspondence: paulagpinto@gmail.com

'Serviço de Pneumologia II, Centro Hospitalar Lisboa Norte-Hospital Pulido Valente, Lisbon, Portugal

${ }^{2}$ Faculdade de Ciências Médicas, Universidade Nova de Lisboa, Lisboa, Portugal

Full list of author information is available at the end of the article
}

forms of obstructive sleep apnea and their treatment on cardiovascular outcomes remains controversial. The observational study by Buchner et al. [8] showed increased cardiovascular morbidity in mild-moderate OSA patients and demonstrated that OSA treatment improved cardiovascular outcome. They found that cardiovascular events were more frequent in untreated mild-moderate OSA patients, and that OSA treatment was associated with a significant reduction (64\%) in cardiovascular risk, independent of age, gender and pre-existing cardiovascular comorbidities.

Reduced circulating nitrate $\left(\mathrm{NO}_{\mathrm{x}}\right)$ levels, increased urinary norepinephrine (U-NE) levels and increased blood pressure (BP) have been described in patients with severe OSA, and are reverted by CPAP [9-17]. The effect of CPAP on these parameters has, however, not been studied in mild-moderate OSA. Previous studies evaluating $\mathrm{NO}_{\mathrm{x}}$ deficiency and sympathetic dysfunction have mainly focused on patients with severe OSA.

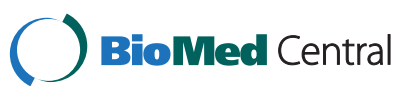


To address this issue, we designed a prospective study that sought to: 1) compare $\mathrm{NO}_{\mathrm{x}}$ and U-NE levels between male patients with mild-moderate and severe OSA; 2) compare BP values between these patient groups, and 3) determine whether CPAP therapy improves $\mathrm{NO}_{\mathrm{x}}$ deficiency, sympathetic dysfunction and $\mathrm{BP}$ in these patients.

\section{Methods}

\section{Study population}

All patients were recruited from our institution's sleep laboratory. OSA was diagnosed on the basis of symptoms and a respiratory disturbance index (RDI) showing more than 5 respiratory events/h on overnight polysomnography. We recruited 67 consecutive male patients with OSA: 36 with mild-moderate OSA and 31 with severe OSA.

Patients were excluded if they met any of the following criteria: 1) current smoker; 2) respiratory or cardiac disease (except for arterial hypertension); 3) renal, hepatic or psychiatric disorder; 4) diabetes mellitus or dyslipidemia; 5) rhinitis, sinusitis or acute illness; 6) daytime hypoxemia or hypercapnia; 7) therapy with oral nitrates, angiotensinconverting enzyme inhibitors, beta-blockers, statins or non-steroidal anti-inflammatory drugs; 8) presence of central respiratory events on polysomnography; 9) previous CPAP therapy or uvulopalatopharyngoplasty. One patient from each group was also excluded because of failure to comply with CPAP.

Patients were assessed for obstructive/restrictive lung disease by a respiratory physician based on clinical evaluation, pulmonary function testing, arterial blood gas measurement and chest radiography, and for cardiac disease by a cardiologist based on history, physical examination, electrocardiography and echocardiography.

As recommended for the measurement of $\mathrm{NO}_{\mathrm{x}}$ levels, all subjects were instructed to ingest a low nitrate/nitrite diet [18]. They were also advised to avoid exercise on urine collection days.

The study protocol was approved by Centro Hospitalar Lisboa Norte's Ethics Committee and all subjects gave written informed consent. The study was performed in accordance with the guidelines in the current revision of the Declaration of Helsinki.

\section{Study design}

We performed a single-center, prospective study of OSA patients. Data were collected in all subjects at baseline and after 1 month of CPAP. These data included full poly-somnography, ambulatory blood pressure monitoring (ABPM), fasting venous blood collection at $11 \mathrm{pm}$, 4 am and 7 am for NOx levels and 24-h urine collection for U-NE. Epworth sleepiness scale was administered at all visits.

\section{Polysomnography}

All subjects underwent full polysomnography (Embla S7000, Embla, USA). Sleep stages were manually scored according to the criteria of Rechtschaffen and Kales [19]. Respiratory events were classified according to the recent scoring recommendations [20]. Apnea was defined as a reduction of $>90 \%$ in oronasal airflow lasting $\geq 10$ seconds. Hypopnea was defined as a decrease of $>30 \%$ in oronasal airflow lasting $\geq 10$ seconds and associated with $\geq 4 \%$ desaturation from the pre-event baseline. Respiratory effort related arousals were defined as a sequence of breaths lasting at least 10 seconds characterized by flattening of the nasal pressure waveform and leading to an arousal from sleep. OSA was defined when RDI was $\geq 5$ events/h (mild-moderate was defined as RDI $<30$ and severe as RDI $\geq 30$ ).

\section{CPAP therapy}

One week after the initial visit, an automated pressure setting device (AutoSet Spirit, ResMed, Australia) was given to all patients with predefined settings (minimal pressure: $4 \mathrm{cmH}_{2} \mathrm{O}$; maximal pressure: $16 \mathrm{cmH}_{2} \mathrm{O}$ ) and they were instructed to use this for 1 month. CPAP adaptation was performed by a sleep technician and patients underwent an educational program for appropriate use of the equipment. Patients were considered compliant with CPAP if they used it for $\geq 4.5 \mathrm{~h} /$ night. Follow-up program consisted of weekly phone calls and immediate correction of adverse effects with optimization of CPAP settings, if necessary.

\section{Ambulatory blood pressure monitoring}

All patients underwent ABPM with a non-invasive portable validated recorder (Spacelab 90207, SpaceLabs Medical, Redmond, WA, USA) at baseline and after 1 month of CPAP. A BP cuff was fitted on the non-dominant arm of the patient for $24 \mathrm{~h}$. BP was recorded every 20 min during the day and every 30 min during the night. A dipping pattern was defined as a reduction in the average systolic $\mathrm{BP}$ at night of $>10 \%$ compared with daytime values. Based on ABPM, hypertension was classified according to the recent guidelines for the management of arterial hypertension [21]. For ethical reasons, anti-hypertensive treatment was not withdrawn during the study.

\section{Blood sample collection and measurement of $\mathrm{NO}_{\mathrm{x}}$}

An intravenous catheter was inserted into an antecubital vein and was kept patent by a continuous saline drip.

Plasma $\mathrm{NO}_{\mathrm{x}}$ levels were determined by the chemiluminescence technique, using a Sievers 280 NO Analyzer (Sievers Instruments) as previously described [22-24]. 


\section{Urinary catecholamines analysis}

Sympathetic nervous system activity was estimated by 24-h U-NE levels using high-performance liquid chromatography as previously described $[25,26]$.

\section{Statistical analysis}

Results are presented as mean \pm SD or as percentages. Comparisons between patients with mild-moderate and severe OSA were performed using the non-paired $t$-test or the Mann-Whitney $U$ test when comparing mean values between groups at baseline, and the paired $t$-test when comparing mean values before and after CPAP treatment. Multivariate ANOVA analysis was performed to assess changes in plasma $\mathrm{NO}_{\mathrm{x}}$ levels during the night and to compare these values before and after CPAP.

Subjects were stratified by $\mathrm{BMI}>30$ and $\mathrm{BMI}<30 \mathrm{~kg} /$ $\mathrm{m} 2$ to assess the effects of obesity on NOx and U-NE levels. Association between categorical variables was evaluated by the chi-square test or the Fisher Exact test. Bivariate relationships between variables were determined by Pearson's or Spearman's correlation. A p value of $<0.05$ was considered statistically significant.

Statistical analysis was performed using the Statistical Package for Social Sciences (SPSS) version 17.0 for Windows.

\section{Results}

Table 1 shows characteristics of the study population at baseline and after 1 month of CPAP. Sixty-seven consecutive OSA patients were studied: 36 patients with mild-moderate OSA and 31 patients with severe OSA.

Patients with severe OSA had a significantly higher body mass index (BMI) than patients with mild-moderate OSA $(\mathrm{p}<0.05)$. Also, those patients had more severe oxygen desaturation than mild-moderate OSA $(\mathrm{p}<0.05)$.

Table 1 Characteristics of the study population at baseline and after 1 month of CPAP

\begin{tabular}{|c|c|c|c|c|}
\hline & \multicolumn{2}{|c|}{ Mild/moderate OSA patients $(n=36)$} & \multicolumn{2}{|c|}{ Severe OSA patients $(n=31)$} \\
\hline & Baseline & Post CPAP & Baseline & Post CPAP \\
\hline$\overline{\text { Age (yrs) }}$ & $48 \pm 10.4$ & NA & $51 \pm 6.3$ & NA \\
\hline Body mass index $\left(\mathrm{Kg} / \mathrm{m}^{2}\right)$ & $29 \pm 3.8^{*}$ & $30 \pm 3.8$ & $35 \pm 5.1^{*}$ & $35 \pm 5.0$ \\
\hline Epworth score & $11 \pm 6.2^{\#}$ & $3.1 \pm 2.5$ & $12 \pm 6.3^{\#}$ & $4.2 \pm 3.2$ \\
\hline $\mathrm{RDI}(\mathrm{n} / \mathrm{h})$ & $16 \pm 6.8^{*}$ & $\# 3 \pm 2.5$ & $66 \pm 24.2^{\#}$ & $4 \pm 2.3$ \\
\hline Mean $\mathrm{SaO}_{2}(\%)$ & $95 \pm 1.3^{*}$ & $\# 96 \pm 1.2$ & $91 \pm 4.8^{\#}$ & $95 \pm 1.2$ \\
\hline Minimum $\mathrm{SaO}_{2}(\%)$ & $86 \pm 4.8^{*}$ & $\# 93 \pm 2.1$ & $71 \pm 9.9^{\#}$ & $93 \pm 2.2$ \\
\hline $\mathrm{SaO}_{2}<90 \%$ (\% of TST) & $1 \pm 3.2^{*}$ & \# $0 \pm 0.2$ & $27 \pm 26.6^{\#}$ & $0 \pm 0.1$ \\
\hline ODI (n/h) & $10 \pm 9.5^{*}$ & ${ }^{\#} 0 \pm 0.2$ & $52 \pm 20.5^{\#}$ & $0 \pm 0.2$ \\
\hline Arousal index (n/h) & $23 \pm 8.1^{*}$ & $\# 16 \pm 9.2$ & $53 \pm 18^{\#}$ & $14 \pm 7$ \\
\hline Compliance (h/night) & NA & $6.3 \pm 1.3$ & NA & $6.6 \pm 0.9$ \\
\hline $95^{\text {th }}$ percentile CPAP pressure $\left(\mathrm{cmH}_{2} \mathrm{O}\right)$ & NA & $11.5 \pm 1.8$ & NA & $13.2 \pm 1.5$ \\
\hline 24h MAP (mmHg) & $91 \pm 6.8^{*}$ & $92 \pm 6.9$ & $97 \pm 8.1^{\#}$ & $92 \pm 9$ \\
\hline \multicolumn{5}{|l|}{ Daytime BP (mmHg) } \\
\hline Systolic & $127 \pm 8.3^{*}$ & $127 \pm 8.8$ & $134 \pm 10.9^{\#}$ & $130 \pm 10.1$ \\
\hline Diastolic & $81 \pm 6.2^{*}$ & $70 \pm 7.5$ & $85 \pm 5.8^{\#}$ & $80 \pm 6.2$ \\
\hline \multicolumn{5}{|l|}{ Nighttime BP (mmHg) } \\
\hline Systolic & $114 \pm 7.9^{*}$ & $116 \pm 10.3$ & $125 \pm 14.2^{\#}$ & $119 \pm 12.9$ \\
\hline Diastolic & $70 \pm 7.6^{*}$ & $70 \pm 7.5$ & $76 \pm 9.3^{\#}$ & $73 \pm 8.9$ \\
\hline $\mathrm{No}_{x} 11 \mathrm{pm}(\mu \mathrm{m})$ & $34.3 \pm 21.8^{+}$ & $41.3 \pm 22.2$ & $34.5 \pm 21.9^{\&}$ & $41.4 \pm 19.8$ \\
\hline $\mathrm{No}_{x} 4 \mathrm{am}(\mu \mathrm{m})$ & $29.4 \pm 15.4^{+}$ & $37.7 \pm 21.1$ & $27.2 \pm 14.4^{\&}$ & $37.4 \pm 17.9$ \\
\hline $\mathrm{No}_{x} 7 \mathrm{am}(\mu \mathrm{m})$ & $26.4 \pm 14.1^{+}$ & $36.6 \pm 19.5$ & $24.3 \pm 16.8^{\&}$ & $35.2 \pm 16.7$ \\
\hline$\Delta \mathrm{NO}_{\mathrm{X}}(\%)$ & $16.5 \pm 18.5^{+}$ & $9.3 \pm 16.3$ & $27.6 \pm 20.1^{\&}$ & $0.79 \pm 52.2$ \\
\hline U-NE ( $\mu \mathrm{g} / 24 \mathrm{~h})$ & $48.5 \pm 19.9^{*}$ & $47 \pm 21.3$ & $73.9 \pm 30.1^{\#}$ & $55.4 \pm 21.8$ \\
\hline
\end{tabular}

Values shown as mean $\pm \mathrm{SD}$. $\mathrm{RDI}$, respiratory disturbance index; $\mathrm{SaO}_{2}$, arterial oxygen saturation; TST, total sleep time; ODI, oxygen desaturation index; MAP, mean arterial pressure; $\mathrm{BP}$, blood pressure; $\mathrm{NO}_{x}$, nitrate levels; $\Delta \mathrm{NO}_{x}$, percentage decrease in $\mathrm{NO}_{\mathrm{x}}$ during the night; U-NE, urinary norepinephrine; $\mathrm{NA}$, Not applicable. *: $\mathrm{p}<0.05$ comparison of baseline values between patients with severe and mild-moderate OSA (unpaired $t$-test). $\#: \mathrm{p}<0.05$ comparison between pre- and post-CPAP values (paired $t$-test).

$+p<0.05$ comparison between different time points and between pre- and post-CPAP for patients with mild-moderate OSA (multivariate ANOVA analysis).

$\& p<0.05$ comparison between different time points and between pre- and post-CPAP for patients with severe OSA (multivariate ANOVA analysis). 


\section{Before CPAP}

At baseline, $61 \%$ of patients with severe OSA and 53\% of patients with mild-moderate OSA had excessive daytime sleepiness with an Epworth sleepiness scale (ESS) score $>10 \quad(p=0.80)$. After CPAP, excessive daytime sleepiness was completely reversed in all patients with severe OSA and in $94 \%$ of patients with mild-moderate OSA (2 mild-moderate patients still had an ESS score $>10$ after CPAP; $\mathrm{p}=0.13$ ).

Patients with severe OSA had significantly higher BP values than patients with mild-moderate OSA (Table 1). Before CPAP, $83 \%$ of patients with severe OSA compared with $69 \%$ of patients with mild-moderate OSA had arterial hypertension $(p=0.93)$, however only $31 \%$ of patients with severe OSA and $29 \%$ with mildmoderate OSA were treated for hypertension. All treated hypertensive patients with mild-moderate OSA had controlled BP levels at baseline and 39\% of them showed a non-dipper nocturnal pressure pattern. In contrast, 55\% of patients with severe OSA showed a non-dipper pattern ( $p>0.05)$. The hypertensive medications were: calcium antagonists, diuretics and angiotensin II receptor antagonists.

Before CPAP, there were no differences in $\mathrm{NO}_{\mathrm{x}}$ levels between patients with mild-moderate and severe OSA for all times measured. $\mathrm{NO}_{\mathrm{x}}$ levels showed a significant decrease during the night in both groups $(\mathrm{p}<0.001)$ (Table 1, Figure 1). The percentage of $\mathrm{NO}_{\mathrm{x}}$ reduction during the night $\left(\Delta \mathrm{NO}_{\mathrm{x}}\right)$ was significantly higher in patients with severe OSA than in patients with mildmoderate OSA $(27.6 \pm 20.1 \%$ vs $16.5 \pm 18.5 \%, p<0.05)$.

24-h U-NE levels were significantly higher in patients with severe OSA than in patients with mild-moderate OSA $\quad(73.9 \pm 30.1$ vs $48.5 \pm 19.91 \mu \mathrm{g} / 24 \mathrm{~h}, \quad \mathrm{p}<0.05)$ (Table 1, Figure 2). There was a significant correlation between U-NE levels and the sleep parameters RDI $(\mathrm{r}=0.63 ; \mathrm{p}<0.001)$, mean $\mathrm{SaO}_{2}(\mathrm{r}=-0,47 ; \mathrm{p}<$ 0.001), minimum $\mathrm{SaO}_{2}(\mathrm{r}=-0.55 ; \mathrm{p}<0.001)$ and arousal index $(\mathrm{r}=0.59 ; \mathrm{p}<0.001)$.

The study population was also stratified by $\mathrm{BMI}>30$ and $<30 \mathrm{~kg} / \mathrm{m} 2$ and there was no difference between obese and non obese subjects in NOx and U-NE levels.

\section{After CPAP}

All patients who completed the study were CPAP compliant. Compliance was similar in the mild-moderate and severe groups $(6.3 \pm 1.3$ vs $6.6 \pm 0.9 \mathrm{~h} /$ night; $\mathrm{p}>$ 0.05). $95^{\text {th }}$ percentile CPAP pressure was $11.5 \pm 1.8 \mathrm{~cm}$ $\mathrm{H}_{2} \mathrm{O}$ in patients with mild-moderate OSA and $13.2 \pm 1.5$ $\mathrm{cm} \mathrm{H}_{2} \mathrm{O}$ in patients with severe OSA $(\mathrm{p}<0.001)$. BMI did not change significantly during the study period. RDI and $\mathrm{SaO}_{2}$ indexes normalized in both patient groups.

After CPAP, both groups had a rise in $\mathrm{NO}_{x}$, although in patients with mild-moderate OSA rise in NOx did not reach full statistical significance $(\mathrm{p}=0.054$; Figure 1 , Table 1). Comparison of the percentage in $\mathrm{NO}_{x}$ level reduction during the night $\left(\Delta \mathrm{NO}_{\mathrm{x}}\right)$ pre- and post-CPAP showed a significant decrease only in patients with severe OSA $(27.6 \pm 20.1 \%$ vs $0.79 \pm 52.2 \%$; $\mathrm{p}<0.05)$.

Evaluation of sympathetic activity showed a significant reduction in 24-h U-NE excretion after CPAP only in patients with severe OSA $(73.9 \pm 30.1$ to $55.4 \pm 21.8 \mu \mathrm{g} /$ $24 \mathrm{~h} ; \mathrm{p}<0.05$ ) (Table 1, Figure 2). Patients with severe OSA had higher post-CPAP U-NE levels than patients with mild-moderate OSA, however the difference was not statistically significant.

After 1 month of CPAP, patients with severe OSA had a significant decrease in 24-h MAP $(\mathrm{p}<0.05)$, daytime systolic BP $(\mathrm{p}<0.05)$ and diastolic BP $(\mathrm{p}<0.05)$, and also night-time systolic BP $(\mathrm{p}<0.05)$ and diastolic BP $(\mathrm{p}<0.05)$. CPAP did not change $\mathrm{BP}$ in patients with mild-moderate OSA. However, it is worth noting that final BP values of patients with severe OSA were similar to BP levels of patients with mild-moderate OSA. Normal circadian dipper pattern was not restored in non-dipper patients after 1 month of CPAP.

\section{Discussion}

Our study showed that there was a significant decrease in plasma $\mathrm{NO}_{\mathrm{x}}$ levels during the night in patients with both severe and mild-moderate OSA before CPAP, with the percentage reduction being higher in patients with severe OSA. After 1 month of CPAP, there was a significant increase in $\mathrm{NO}_{\mathrm{x}}$ levels in patients with severe OSA
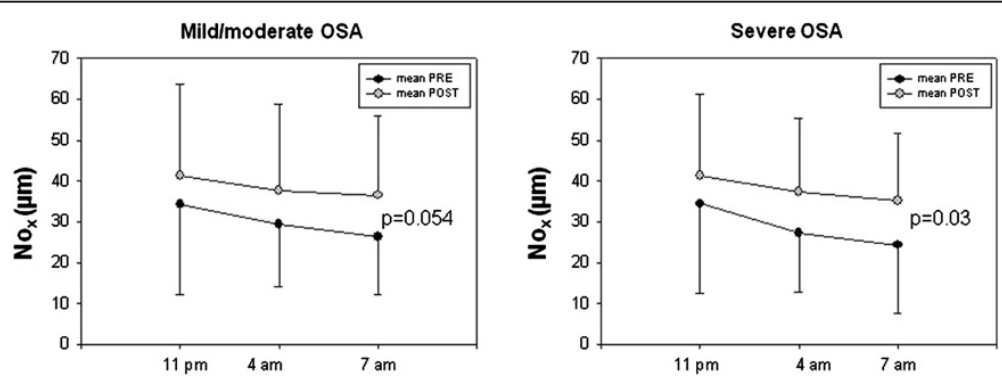

Figure 1 NOx levels at different time points before and after 1 month of CPAP in patients with mild-moderate and severe OSA. 


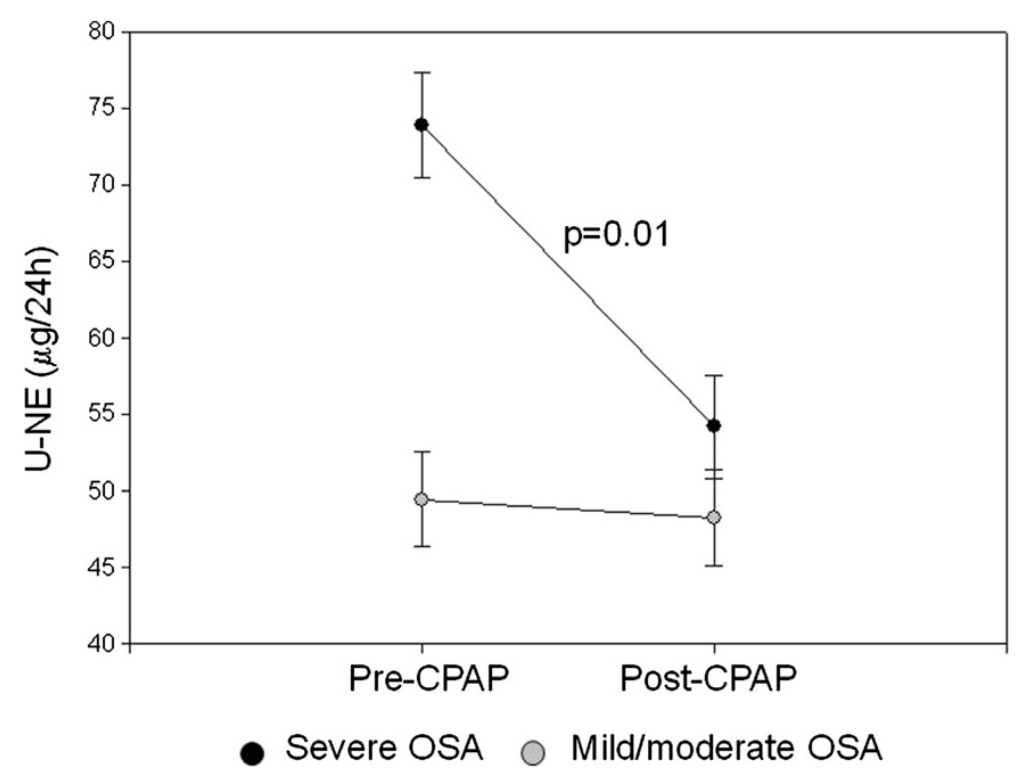

Figure 2 U-NE levels before and after 1 month of CPAP in patients with mild-moderate and severe OSA.

and a non-significant increase in patients with mildmoderate OSA. We demonstrated that patients with severe OSA had higher baseline U-NE levels than patients with mild-moderate OSA. After 1 month of CPAP, only patients with severe OSA had significantly decreased U-NE levels compared with pre-CPAP levels. We also found that 1 month of CPAP treatment reduced BP values only in patients with severe OSA.

The main strengths of our study were the experimental design (determination of $\mathrm{NO}_{\mathrm{x}}$ levels during the night) and the comparison between two groups of patients with different OSA severity.

\section{$\mathrm{NO}_{x}$ deficiency}

Diet is a contributor to $\mathrm{NO}_{\mathrm{x}}$ levels [18] which has not been addressed in previous studies [9,12]. In our study all subjects were instructed to ingest a low nitrate/nitrite diet.

Previous studies have demonstrated that $\mathrm{NO}_{\mathrm{x}}$ production is reduced in severe OSA $[9,10,12]$. We further evaluated different severity OSA patient groups through the night. We demonstrated a significant decrease in $\mathrm{NO}_{\mathrm{x}}$ levels during the night in patients with mild-moderate and severe OSA, with a higher percentage reduction in $\mathrm{NO}_{x}$ levels in patients with severe OSA. Lavie et al. also reported a decrease in $\mathrm{NO}_{x}$ levels during the night in eight patients with severe OSA [11].

There is some evidence that hypoxemia associated with apnea could lead to decreased nitric oxide production. As oxygen is a cosubstrate of nitric oxide (NO) synthase (NOS), OSA related desaturations might result in depressed synthesis of NO. Night-time hypoxia might suppress the transcription of the endothelial NOS gene and the stability of its mRNA, as suggested by cell culture experiments performed under hypoxic conditions [27]. It has been demonstrated that NOS inhibitors are increased in OSA and might contribute to lowered NO levels [28].It is also possible that free oxygen radicals generated by circulating neutrophils under conditions of hypoxia-reoxygenation in untreated OSA might cause an exaggerated destruction of NO [29]. These mechanisms were not evaluated in the present study.

Previous studies have shown that in patients with severe OSA, CPAP therapy to abolish sleep apnea results in increased $\mathrm{NO}_{\mathrm{x}}$ levels, suggesting that whatever mechanism causes the suppression of NO synthesis or release is acute and promptly reversible with the reversal of sleep apnea [9-12]. Our study confirmed these results, but did not show an increase in $\mathrm{NO}_{\mathrm{x}}$ levels in mildmoderate patients. However, this finding could be related to low statistical power. Indeed, a higher sample would probably reach statistical significance.

\section{Sympathetic dysfunction}

Previous studies have demonstrated high U-NE levels in severe OSA patients [13-17]. Our findings showed significantly higher 24-h U-NE levels in patients with severe OSA compared with patients with mild-moderate OSA. U-NE levels correlated with RDI, overnight oxygen desaturation and arousal index, suggesting that hypoxemia and sleep fragmentation increased sympathetic activity.

It has also been shown that CPAP reduces U-NE levels in patients with severe OSA $[13,15,17]$. Our study confirmed these results for patients with severe OSA and demonstrated that there was no change in U-NE levels following CPAP in patients with mild-moderate OSA. The mechanisms explaining this observation are unclear, 
but we propose that in patients with mild-moderate OSA, the overnight oxygen desaturation and the arousal index related to respiratory events were not sufficient to activate the sympathetic nervous system and thereby modify U-NE levels. After 1 month of CPAP, U-NE levels of patients with severe OSA were not significantly different from those with mild-moderate OSA.

\section{Blood pressure}

Previous studies have demonstrated that CPAP reduces BP in patients with severe OSA [30-32]. This study also found that both systolic and diastolic BP was reduced in daytime and night-time measurements in patients with severe OSA. In patients with mild-moderate OSA, no change in BP values was found; however these patients already had their BP controlled within the normal range at baseline. AlonsoFernández [12] also found that normotensive patients did not change their $\mathrm{BP}$ values after CPAP.

The meta-analysis by Haentjens [33] showed that greater CPAP related reductions in ambulatory BP were observed in patients with more severe OSA and a better nightly use of CPAP.

In our study, differences in the effects of CPAP on BP between patients with mild-moderate OSA and patients with severe OSA could not be explained by differences in compliance rates, as compliance was similar between groups. The high rate of CPAP compliance might be explained by a very comprehensive follow-up program with weekly phone calls and immediate correction of adverse effects.

The non-reversal of the circadian BP pattern in our patients might be due to the short period of CPAP treatment. In the study by Martinez Garcia [30], normalization of the nocturnal BP pattern occurred after three months of CPAP.

In this study, we found that 1 month of CPAP therapy did not change $\mathrm{NO}_{x}$ levels, 24-h U-NE levels or BP values in patients with mild-moderate OSA. The absence of response of one clinical parameter (BP) and two biological markers $\left(\mathrm{NO}_{\mathrm{x}}\right.$ and U-NE) to CPAP therapy could suggest that physiological effects of mild-moderate OSA may not be disruptive enough to stimulate a rise in U-NE and BP, as does severe OSA. It could also be that a 1 month of CPAP was not enough to detect differences between the groups. Also, CPAP might not have a protective cardiovascular effect in less severe forms of OSA. Indeed, mortality follow-up of the Wisconsin Sleep Cohort, including 20,963 subjects, indicated that only patients with severe OSA had a significantly increased cardiovascular mortality risk [34].

Limitations:

Some limitations should be addressed in our study, namely a low sample population could compromise statistical power. Also, our data are unable to generalize to female, as we did not include women.

As apnea hypopnea index is more often referred in the literature, using RDI could difficult the comparison between studies. Also, the maintenance of antihypertensive therapy could have confounded results. The short time of CPAP treatment is another possible limitation, as a longer study period may have produced different results. In the study by Martinez Garcia et al. [30], normalization of the nocturnal BP pattern occurred after three months of CPAP.

As our results may have implications for the CPAP treatment of patients with mild-moderate OSA, it is important to undertake a larger controlled study with a longer follow-up period.

\section{Conclusions}

Our study demonstrated that 1 month of CPAP treatment significantly increases plasma $\mathrm{NO}_{\mathrm{x}}$ levels and reduces 24-h U-NE levels and BP in patients with severe OSA, but did not demonstrate a significant change in these values in patients with mild-moderate OSA.

\section{Competing interests}

The authors declare that they have no competing interests.

\section{Authors' contributions}

PP participated in study conception, design and data acquisition, and drafting of the manuscript. CB participated in study conception and design and drafting of the manuscript. JM participated in drafting of the manuscript. $\mathrm{RP}$ and MG performed the $\mathrm{NO}_{x}$ analysis. MC and MM participated in study design. CM and AD performed the polysomnographies. MG participated in study design. All authors read and approved the final manuscript.

\section{Acknowledgements}

We thank Dr Baltazar Nunes for assistance with the statistical analysis and Dr Júlio Calaça and Dr Paula Calaça for ABPM analysis.

\section{Funding}

This study was funded by Feder/POCI/FCT/Centro de Estudos de Doenças Crónicas.

\section{Author details}

'Serviço de Pneumologia II, Centro Hospitalar Lisboa Norte-Hospital Pulido Valente, Lisbon, Portugal. 'Faculdade de Ciências Médicas, Universidade Nova de Lisboa, Lisboa, Portugal. ${ }^{3}$ Centro de Estudos de Doenças Crónicas, Lisbon, Portugal. ${ }^{4}$ Hospital Clinic. CIBERES. IDIBAPS, Barcelona, Spain.

Received: 9 March 2011 Accepted: 28 February 2013

Published: 13 March 2013

\section{References}

1. Shahar E, Whitney CW, Redline S, Lee ET, Newman AB, Nieto FJ, O'connor GT, Boland LL, Schwartz JE, Samet JM: Sleep-disordered breathing and cardiovascular disease: cross-sectional results of the Sleep Heart Health Study. Am J Respir Crit Care Med 2001, 163:19-25.

2. Peppard PE, Young T, Palta M, Skatrud J: Prospective study of the association between sleep-disordered breathing and hypertension. N Engl J Med 2000, 342:1378-1384.

3. Nieto FJ, Young TB, Lind BK, Shahar E, Samet JM, Redline S, D'Agostino RB, Newman AB, Lebowitz MD, Pickering TG, for the Sleep Heart Health Study: Association of sleep-disordered breathing, sleep apnea and hypertension in a large community-based study. JAMA 2000, 283:1829-1836. 
4. McNicholas WT, Bonsignore MR, and the Management Committee of EU COST ACTION B26: Sleep apnoea as an independent risk factor for cardiovascular disease: current evidence, basic mechanisms and research priorities. Eur Respir J 2007, 29:156-178.

5. Bradley TD, Floras JS: Obstructive sleep apnea and its cardiovascular consequences. Lancet 2009, 373:82-93.

6. Loube DI, Gay PC, Strohl KP, Pack Al, White DP, Collop NA: Indications for positive airway pressure treatment of adult obstructive sleep apnea patients. Chest 1999, 115:863-866.

7. Kushida CA, Littner MR, Hirshkowitz M, et al: Practice parameters for the use of continuous and bilevel positive airway pressure devices to treat adult patients with sleep-related breathing disorders. Sleep 2006, 29:375-380.

8. Buchner NJ, Sanner BM, Borgel J, Rump LC: CPAP treatment of mild to moderate obstructive sleep apnea reduces cardiovascular risk. Am J Respir Crit Care Med 2007, 176:1274-1280.

9. Ip MSM, Lam B, Chan L, Zheng L, Tsang KWT, Fng PCW, Lam W: Circulating nitric oxide is suppressed in obstructive sleep apnea and is reversed by nasal continuous positive airway pressure. Am J Respir Crit Care Med 2000, 162:2166-2171.

10. Schulz R, Schmidt D, Blum A, Lopes-Ribeiro X, Lucke C, Mayer K, Olschewski $H$, Seeger W, Grimminger F: Decreased plasma levels of nitric oxide derivatives in obstructive sleep apnoea: response to CPAP therapy. Thorax 2000, 55:1046-1051.

11. Lavie L, Hefetz A, Luboshitzky R, Lavie P: Plasma levels of nitric oxide and $\mathrm{L}$-arginine in sleep apnea patients. Effects of nCPAP treatment. J Mol Neurosci 2003, 21:57-63.

12. Alonso-Fernández A, Garcia-Rio F, Arias MA, Hernanz A, Peña M, Pierola J, Barceló A, López-Collazo E, Garcia AA: Effects of CPAP upon oxidative stress and nitrate efficiency in sleep apnoea. A randomized trial. Thorax 2009, 64:581-586.

13. Sukegawa M, Noda A, Sugiura T, Nakata S, Yoshizaki S, Soga T, Yasuda Y, Iwayama N, Nakai S, Koike Y: Assessment of continuous positive airway pressure treatment in obstructive sleep apnea syndrome using 24-hour urinary catecholamines. Clin Cardiol 2005, 28:519-522.

14. Elmasry A, Lindberg E, Hedner J, Janson C, Boman G: Obstructive sleep anoea and urine catecholamines in hypertensive males: a populationbased study. Eur Respir J 2002, 19:511-517.

15. Hedner J, Darpo B, Ejnell H, Carlson J, Caidahl K: Reduction in sympathetic activity after long-term CPAP treatment in sleep apnoea: cardiovascular implications. Eur Respir J 1995, 8:222-229.

16. Marrone O, Riccobono L, Salvaggio A, Mirabella A, Bonanno A, Bonsignore MR: Catecholamines and blood pressure in obstructive sleep apnea syndrome. Chest 1993, 103:722-727.

17. Ziegler MG, Mills PJ, Loredo JS, Ancoli-Israel S, Dimsdale JE: Effect of continuous positive airway pressure and placebo treatment on sympathetic nervous activity in patients with obstructive sleep apnea. Chest 2001, 120:887-893.

18. Wang J, Brown MA, Tam SH, Chan MC, Whitworth JA: Effects of diet on measurement of nitric oxide metabolites. Clinical and Experimental Pharmacology and Physiology 1997, 24:418-420.

19. Rechtschaffen A, Kales A: A manual of standardized terminology, techniques and scoring system for sleep stages of human subjects. Education and Welfare Public Health Service - NIH/NIND: US Department of Health; 1968

20. Iber Cl, Ancoli-Israel S, Chesson L, Quan S: for the American Academy of Sleep Medicine. Rules, terminology and technical specifications: The AASM Manual for the Scoring of Sleep and Associated Events; 2007.

21. Mancia G, Backer G, Dominiczack A, Cifkova R, Fagard R, Germano G, Grassi G, Heagerty A, Kjeldsen S, Laurent S, Narkiewicz K, Ruilope L, Rynkiewicz A, Schmieder R, Boudier H, Zanchetti A: Guidelines for the management of arterial hypertension. The task force for the management of arterial hypertension of the European Society of Hypertension (ESH) ad of the European Society of Cardiology (ESC). Journal of Hypertension 2007 25:1105-1187

22. Yang F, Troncy E, Francoeur M, Vinet B, Vinay P, Czaika G, Blaise G: Effects of reducing reagents and temperature on conversion of nitrite and nitrate to nitric oxide and detection of NO by chemiluminescence. Clin Chem 1997, 43:657-662.

23. Cox RD, Frank CW: Determination of nitrate and nitrite in blood and urine by chemiluminescence. J Anal Toxicol 1982, 6:148-152.
24. Braman RS, Hendrix SA: Nanogram nitrite and nitrate determination in environmental and biological materials by vanadium (III) reduction with chemiluminescence detection. Anal Chem 1989, 61:2715-2718.

25. Macdonald IA, Lake DM: An improved technique for extracting catecholamines from body fluids. J Eurosci Meth 1985, 13:239-248.

26. Laederach $\mathrm{K}$, Weidmann P: Pasma and urinary catecholamines as related to renal function in man. Kidney Inc 1987, 31:107-111.

27. McQuillan LP, Leung GK, Marsden PA, et al: Hypoxia inhibits expression of eNOS via transcriptional and post-transcriptional mechanisms. Am J Physiol 1994, 267:1921-1927.

28. Carlson J, Hedner J, Pettersson A: Increased plasma concentration of ADMA, a naturally occurring nitric oxde synthesis inhibitor in OSA patients. Am J Respir Crit Care Med 1997, 155:A869.

29. Schulz R, Mahmoudi S, Hattar K, et al: Enhanced release of superoxide from polymorphonuclear neutrophils in obstructive sleep apnea: impact of CPAP therapy. Am J Respir Crit Care Med 2000, 162:566-570.

30. Martinez-Garcia MA, Gómez-Aldaravi R, Soler-Cataluna JJ, Martinez TG, Bernácer-Alpera B, Román-Sánchez P: Positive effect of CPAP treatment on the control of difficult-to-treat hypertension. Eur Respir J 2007, 29:951-957.

31. Pepperell JC, Ramdassing-Dow S, Crosthwaite N, Mllins R, Jenkinson C, Stradling JR, Davies RJO: Ambulatory blood pressure after therapeutic and subtherapeutic nasal continuous positive airway pressure for obstructive sleep apnoea: a randomised parallel trial. Lancet 2002, 359:204-210.

32. Faccenda JF, Mackay TW, Boon NA, Douglas NJ: Randomized placebocontrolled trial of continuous positive airway pressure on blood pressure in the sleep apnea-hypopnea syndrome. Am J Respir Crit Care Med 2001, 163:344-348.

33. Haentjens P, Van Meerhaeghe A, Moscariello A, Weerdt S, Poppe K, Dupont A, Velkeniers B: The impact of continuous positive airway pressure on blood pressure in patients with obstructive sleep apnea syndrome. Evidence from a meta-analysis of plaebo-controlled randomized trials. Arch Intern Med 2007, 167:757-765.

34. Young T, Finn L, Peppard PE, Szklo-Coxe M, Austin D, Nieto J, Stubb R, Hla KM: Sleep disordered breathing and mortality: eighteen-year follow-up of the Wisconsin Sleep Cohort. Sleep 2008, 31:1071-1078.

doi:10.1186/1471-2466-13-13

Cite this article as: Pinto et al.: Effects of CPAP on nitrate and norepinephrine levels in severe and mild-moderate sleep apnea. $B M C$ Pulmonary Medicine 2013 13:13

\section{Submit your next manuscript to BioMed Central and take full advantage of:}

- Convenient online submission

- Thorough peer review

- No space constraints or color figure charges

- Immediate publication on acceptance

- Inclusion in PubMed, CAS, Scopus and Google Scholar

- Research which is freely available for redistribution

Submit your manuscript at www.biomedcentral.com/submit
C) Biomed Central 